UDC: 330.101[658.62-028.63]:161.14+005.9

DOI: 10.26697/ijes.2019.4.41

\section{Digital Product: The Essence of the Concept and Scopes}

\author{
Associate Professor Pypenko I. S. ${ }^{\mathbf{1 , 2}}$ \\ ${ }^{1}$ Simon Kuznets Kharkiv National University of \\ Economics, Ukraine \\ ${ }^{2}$ Scientific Research Institute KRPOCH, Ukraine
}

\begin{abstract}
Background:

The development of the IT sphere, the creation, use and storage of information in digital format has contributed to the emergence of a new type of products - digital. Today, there is no definition of the term "digital product" in academic reference books, dictionaries, articles, etc.

The aim of the study - to introduce the concept "digital product" into the academic circulation, to define the current state and promising scopes of digital products.
\end{abstract}

\section{Methods: \\ To substantiate the essence of the concept "digital product", the following complex of theoretical research methods has been used: deduction and induction, analysis and synthesis, comparison, generalization, systematization and interpretation of results.}

\section{Results:}

Academic literature, an online resource on the use of the term "digital product" have been studied. It has been found that the concept "digital product" is absent in contemporary literature.

The study of the phenomenon "digital product" required the introduction into the academic circulation of the concept, the definition of the current state and promising scopes of its application.

Digital product is an information service and the result of labor, represented in digital format, recorded by a binary code.

Digital products can be made from physical objects or as a standalone digital object.

There are many advantages to a digital product over a product in the physical dimension. For example, the lack of physical deterioration of digital product, the ability to copy it without loss of quality, the ability to transmit electronic communications without material reproduction, and more.

The phenomenon "digital product" creates a fundamentally new system of relationships between market entities, in which the digital product (good, service) and payment for it is made electronically.

The advantages of such relationships are the availability of transactions, regardless of the location of the market entities, at any time of the day and their speed, as well as the confidentiality of the entities. In addition, unlike the product in the physical dimension, the digital product does not have the cost of shipping, packaging, storage, etc.

There is a possibility to upgrade (changes, additions or updates) a digital product. These actions can be regulated: at the state level - by legal framework, at the level of economic entities - by contractual relations.

The need to identify promising scopes of digital products is emerging.

Used spheres for digital products:

- in the economic sphere: "cryptocurrency", "electronic money", "virtual money", "cryptoasset", "digital asset", etc.

- in the legal sphere: laws, legal acts, regulations, instructions, documents, etc.

- in the educational sphere: curriculums, programs, ebooks, audio, graphics, technical documents, software, photographs, etc.

- in the technical sphere: computer programs, television, etc.

The list of used spheres for digital products presented by us is not exhaustive. It merely outlines the main areas and points to the multifacetedness of this phenomenon, which needs further scientific research.

\section{Conclusions:}

Thus, digital information refers to any information contained in the digital format, regardless of its scope. Multifacetedness and multidimensionality of the phenomenon "digital product" reveals large perspectives for research in this field. Further research will focus on identifying the specialties of this phenomenon, as well as methodic of creation, application, storage.

\section{Information about the author: Pypenko Iryna Sergiivna - Doctor of Philosophy in Economics, Associate Professor, Simon Kuznets Kharkiv National University of Economics; Scientific Research Institute KRPOCH, Kharkiv, Ukraine. \\ Research interests: theoretical and methodological problems of economics, digital asset management, digital product; https://orcid.org/0000-0001-5083- 540X.}

\section{Corresponding Author:}

Pypenko Iryna Sergiivna

\section{Corresponding Author's Email:}

edu.center.office@gmail.com 